\title{
Indicadores para avaliação de Qualidade do gerenciamento de recursos humanos em enfermagem
}

\author{
Evaluation of Quality indicators for human resources management in nursing
}

Indicadores para evaluación de la calidad en la administración de los recursos humanos en enfermería

\author{
Paulina Kurganct', Marta Maria Melleiro', Daisy Maria Rizatto Tronchin' \\ 'Universidade de São Paulo. Escola de Enfermagem, Departamento de Orientação Profissional. São Paulo, SP
}

Submissão: 07/03/2008

Aprovação: 15/09/2008

\section{RESUMO}

Estudo Qualitativo, cujo objetivo foi resgatar, junto a docentes de administração em enfermagem, os significados constitutivos de indicadores de Qualidade de gerenciamento de recursos humanos em enfermagem. Participaram dez docentes de uma instituição de ensino pública do Município de São Paulo. A coleta de dados foi realizada através de entrevistas semi-estruturadas e analisadas segundo Bardin. Os achados apontaram para as categorias Dimensão Institucional e Profissional, sendo que na primeira predominou a política de recursos humanos e a participação nos processos decisórios. Na segunda, constatou-se satisfação no trabalho e o absenteísmo. Os indicadores apontados deverão ser aplicados e validados, para a sua consolidação.

Descritores: Indicadores de Qualidade; Recursos humanos; Enfermagem.

\begin{abstract}
This is Qualitative study aiming to retrieve with the academic professors of the nursing administration, the constitutive criteria of Quality indicators of human resources management in Nursing. Ten academic professors of a public teaching institution, in the city of São Paulo, took part of this study. Data collection was performed by means of semi -structured interviews and analyzed according to Bardin. The results pointed out to the Institutional and Professional categories. In the first category, the human resource policy predominated as well as the participation in decisive processes. In the second one, it was observed satisfaction at work and absenteeism. The referred indicators must be applied and validated for their consolidation.
\end{abstract}

Descriptors: Quality indicators; Human resources; Nursing.

\section{RESUMEN}

Este es un estudio cualitativo cuyo objetivo fue de rescatar, junto a los docentes de la administración en enfermería, los significados constitutivos de los indicadores de calidad de esta administración de recursos humanos en Enfermería. Diez docentes de una institución de enseñanza pública del municipio de São Paulo hicieron parte de este estudio. La colecta de datos se realizó a través de entrevistas semiestructuradas según Bardin. Los hallazgos apuntaron para las categorías Dimensión Institucional y Profesional, siendo Que en la primera han predominado la política de recursos humanos y la participación en los procesos decisivos. En la segunda, se verificó la satisfacción en el trabajo y el absentismo. Los indicadores apuntados deben ser aplicados y validados para su consolidación.

Descriptores: Indicadores de calidad; Recursos humanos; Enfermería. 


\section{INTRODUÇÃO}

A qualidade como um conceito abstrato e subjetivo, carece de subsídios concretos e consensuais para ser adotada como ferramenta de avaliação de decisões e ações gerenciais.

No contexto da saúde, Qualidade é um conceito considerado complexo, cujos componentes podem ser agrupados em sete atributos ou pilares fundamentais: eficácia, efetividade, eficiência, otimização, legitimidade, eqüidade e aceitabilidade. Os Quatros primeiros referem-se a atributos Que guardam correlações positivas ou negativas, com elementos inerentes à instituição e os três últimos guardam correlação com atributos inerentes à instituição no Que se refere à sua inserção no contexto político-social e econômico de uma determinada sociedade ${ }^{(1,2)}$.

As modalidades pertinentes à avaliação em saúde consideram a importância de ser revisto os contextos social e institucional para uma melhor compreensão da construção dessas avaliações. As avaliações em saúde, ao se constituírem em uma área incipiente, na construção conceitual e metodológica, podem ser encontradas, na literatura, de forma diversificada ${ }^{(3)}$.

Nesse cenário, a construção de indicadores de Qualidade para a avaliação de serviços de saúde exige a explicitação de referenciais de apoio sob a ótica dos Quais, os diferentes elementos constitutivos das estruturas institucionais, dos processos de trabalho e dos resultados da assistência prestada são resgatados e analisados.

Assim, a elaboração de indicadores deve contemplar eixos condutores Que apontam para a necessidade de serem consideradas as políticas educacionais, assistenciais e gerenciais em saúde; a missão, a visão, as políticas e as estruturas organizacionais; os programas, propostas e os processos de trabalho das instituições de saúde; os recursos humanos, materiais financeiros e físicos disponíveis nesses estabelecimentos e as expectativas da demanda atendida.

Indicador em saúde é conceituado como uma unidade de medida de uma atividade com a Qual se está relacionado ou, ainda, uma medida Quantitativa Que pode ser empregada como um guia para monitorar e avaliar a Qualidade dos cuidados providos ao usuário e as atividades dos serviços; é uma chamada Que identifica ou dirige a atenção para assuntos específicos de resultados dentro de uma organização de saúde, Que devem ser motivos de revisão. Um indicador pode ser uma taxa ou coeficiente, um número absoluto ou um fato ${ }^{(4,5)}$.

Indicadores são considerados variáveis Que medem Quantitativamente as variações no comportamento dos critérios de Qualidade pré-estabelecidos $^{(6)}$.

Outro aspecto a ser considerado na avaliação de serviços de saúde é o paradigma atual Que embasa o gerenciamento de Recursos Humanos (RH) em saúde e Que considera a dimensão humana, no ambiente da Qualidade, o centro das discussões gerenciais, uma vez Que os anseios, as expectativas e a satisfação dos responsáveis em concretizar os propósitos da instituição, são vitais para o alcance das metas institucionais ${ }^{(7)}$.

No âmbito do gerenciamento de recursos humanos, há ainda Que se considerar a importância de serem elaborados indicadores passíveis de análise e comparação com padrões internos e externos à instituição. Cabe ressaltar Que um único indicador dificilmente é capaz de retratar a realidade; é mais provável Que um grupo deles possa explicitar e compor uma determinada situação ${ }^{(8)}$.

Especificamente, na área da enfermagem, para a avaliação da Qualidade do gerenciamento de RH humanos têm-se destacado os seguintes indicadores: percentual de investimento em treinamento por ano e número de horas de treinamento por ano por funcionário, taxa de absenteísmo, de rotatividade e de acidente de trabalho de profissionais de enfermagem ${ }^{(9,10)}$.

Frente ao exposto, faz-se premente a necessidade da elaboração de novos indicadores para avaliar a Qualidade do gerenciamento de RH. Dessa forma, esta peseuisa tem por objetivo resgatar, junto a docentes de administração em enfermagem, os significados constitutivos de indicadores de Qualidade de gerenciamento de $\mathrm{RH}$ em enfermagem.

\section{PERCURSO METODOLÓGICO}

Trata-se de um estudo Qualitativo Que permite o contato e o resgate de informações necessárias ao objeto a ser desvendado, partindo-se da apreensão dos momentos do processo de trabalho Que, na vertente de Mendes Gonçalves ${ }^{(1)}$, refere-se aos nexos estabelecidos no interior do processo de trabalho, neste estudo o processo gerencial, realizado por meio do conhecimento, dos objetivos e da finalidade desse trabalho.

Os preceitos éticos para a realização desta investigação obedeceram à Resolução 196/96 $6^{(12)}$, Que versa sobre as Diretrizes e Normas Regulamentadoras de Pesquisa em Seres Humanos. Dessa maneira, foi elaborado o Termo de Consentimento Livre e Esclarecido e entregue aos sujeitos da pesquisa, em duas vias.

Na busca do conhecimento Que embasasse a construção desses indicadores e para o resgate dos significados Que dessem consistência ao conteúdo dos indicadores a serem criados, foram entrevistadas dez docentes, Que atuam no ensino do Gerenciamento em Enfermagem em uma Universidade Pública do Estado de São Paulo, tendo, como critério de inclusão, o fato de vivenciarem o ensino dessa temática, há mais de cinco anos.

Os dados foram coletados por meio de entrevistas semiestruturadas, pautadas em duas Questões norteadoras: $\mathrm{O}$ Que você entende por Qualidade de gerenciamento de recursos humanos em enfermagem? Na sua vivência o Que você levaria em consideração para avaliar a Qualidade do gerenciamento de recursos humanos em enfermagem?

Para preservar o anonimato das colaboradoras, as mesmas foram identificadas por letras e numeradas de El a ElO.

Os achados foram analisados segundo a Análise de Conteúdo de $\operatorname{Bardin}^{(13)}$, Que possibilitou, pelo conhecimento docente, o resgate de elementos de essencialidade na atribuição dos significados e a, conseQüente, construção de indicadores.

Mediante os discursos das colaboradoras e do resgate das Unidades de Significado (US), as Quais agrupadas por similitude de conteúdos, permitiram extrair duas categorias empíricas: Dimensão Institucional e Dimensão Profissional.

\section{RESULTADOS E DISCUSSÃO}

Na categoria Dimensão Institucional foram albergadas as US, a saber: Dimensionamento AdeQuado de Pessoal; Participação nos Processos Decisórios; Condições de Trabalho; Política de Recursos 
Humanos; Remuneração AdeQuada; Progressão na Carreira e Sobrecarga de Trabalho.

Na categoria Dimensão Profissional foram agrupadas as US: Absenteísmo; Rotatividade de Pessoal; Número de Horas de Treinamento; Satisfação no Trabalho; Afastamento por Acidente de Trabalho e por Doença.

As US Que dão consistência às categorias Dimensão Institucional e Profissional evidenciam as vivências profissionais no cotidiano do trabalho da enfermagem, na ambigüidade das convergências e divergências, Que ocorre na relação de trabalho entre indivíduo e organização. Embora o indivíduo e a organização sejam elementos integrantes "do" e, interdependentes, "no" processo de trabalho, de forma contínua, tendem a gerar um desecuilíbrio de forças nessa relação.

Assim, na categoria Dimensão Institucional resgata-se, pela análise das diferentes US Que a compõem, como são percebidas, pelas docentes, as condições de trabalho e as áreas ou elementos de responsabilidade da instituição no estabelecimento dessas condições. Outro aspecto a ser considerado, na análise dos discursos das participantes, é o fato de, muitas vezes, US com conteúdos aparentemente diferentes, emergirem, em um mesmo momento de uma fala, na mesma linha de pensamento. Um trecho do discurso de E6 esclarece este fato:

“... Índice de satisfação no trabalho depende de outros fatores como grau de descentralização do poder; socialização da informação para tomada de decisão, relações pessoais entre a equipe...".

Quanto à US Dimensionamento Adequado de Pessoal, Gaidzinski, Fugulin e Castilho ${ }^{(14)}$ consideram-na essencial no gerenciamento de RH por "interferir, diretamente na eficácia, na Qualidade e no custo da assistência à saúde". As falas de E4, E2 e E8 referendam essa assertiva:

\section{"... Quantos pacientes seria possível cada profissional assistir?"} (E4)

“... O Quantitativo de pessoal é extremamente importante... Para um paciente de $80 \mathrm{~kg}$ a gente precisa de 4 pessoas".(E2)

“... Se eu avaliar a relação número funcionário de enfermagem/ leitos..." (E8)

A US Participação no Processo Decisório, segundo a docente E6, não é percebida como uma ferramenta gerencial importante somente pela Qualidade do resultado da decisão tomada, mas, pela possibilidade Que a essa participação concede ao enfermeiro, de planejar, monitorar e de transformar seu processo de trabalho. Sua fala exemplifica:

“... A relação de poder é dura no sentido de relações restritivas, de uso de poder coercitivo por parte das chefias, de falta de possibilidade de participação nas atividades... E no planejamento e avaliação das mesmas" (E6).

Em relação à US Condições de Trabalho, diferentes pontos são focados pelas colaboradoras. A informatização do Sistema de Assistência de Enfermagem (SAE), como ferramenta de trabalho, é assim percebida por $(E \mathrm{I})$ :

“O processo de enfermagem informatizado, eu acho Que ele vai ser um senhor indicador para a Qualidade, para o gerenciamento de recursos humanos".

Em outro momento, a mesma colaboradora relaciona a efetividade da capacitação do pessoal às condições de estrutura oferecidas pela instituição:

“... No caso de aumento de úlcera por pressão, para isso vou dar essa capacitação... Aí, não tenho instrumental, não tenho material de curativo, então não adianta dar treinamento... Ele só vai ser indicador Quando eu tiver uma infra-estrutura".

A docente E2, aponta, também, aspectos relativos a recursos materiais ao dizer:

“... Como o trabalhador utiliza os recursos materiais... Porque muitas vezes ele não consegue perceber o Quanto isso implica na Qualificação da assistência".

Nessa perspectiva, é imperativo Que os serviços de saúde assegurarem a Quantidade e a Qualidade dos materiais necessários para Que os profissionais realizem suas atividades sem riscos para si e para o usuário(15).

Outra US considerada pelas docentes do estudo e Que integra a categoria Dimensão Institucional são as Políticas de RH. As políticas institucionais e, entre elas, a de $\mathrm{RH}$ pode ser considerada um instrumento gerencial norteador e determinante de propostas e de processos de trabalho, Que são desenvolvidos nas instituições de saúde. Por outro lado, são as políticas institucionais Que referendam e concretizam as relações de poder Que se estabelecem na dinâmica institucional, conformando a estrutura informal da organização.

"A relação entre política e poder nas organizações dá-se pelo simples fato da política organizacional ser um dos instrumentos de concretização do poder"(16).

Integrando, ainda, a Categoria Dimensão Institucional foi resgatada a US Remuneração Adequada, Que emerge nas falas de várias docentes chamando a atenção para o fato de Que, no cotidiano do trabalho de enfermagem, a remuneração tem sido considerada um fator negativo no gerenciamento de RH. Nesse sentido, a remuneração mostra-se com um significado específico no discurso Que se segue:

"Talvez, o mais evidente nos dias de hoje, é a remuneração que seja mais importante, mas Que está mais em evidência, seria uma política de remuneração adeQuada e justa em relação ao mercado de trabalho...". [E6]

Robbins $^{(17)}$ corrobora com a fala de E6, ao considerar a Teoria da Eqüidade, na Qual o valor monetário tem um significado simbólico, além de seu valor de troca. Segundo esse autor, a remuneração é considerada como primeiro resultado para uma aproximação com um tratamento justo ao determinar se os 
indivíduos são remunerados de maneira justa.

A docente E9 considera Que:

“... A instituição não tem uma política salarial ele (o funcionário) pode ficar 20 anos na empresa Que isso não é considerado... Os benefícios, uma remuneração adeQuada...".

As Teorias do Reforço e da Expectativa, também, atestam o valor monetário como um agente motivador ${ }^{(17)}$.

Outra US integrante da categoria Dimensão Institucional e resgatada no discurso das colaboradoras é a possibilidade de Progressão na Carreira. O depoimento de E6 explicita:

“... Para mim, índice de satisfação no trabalho depende de outros fatores... Por exemplo, possibilidade de progressão na carreira... Definição de plano de carreira dentro da política de RH".

Nessa direção, a Qualidade de Vida do Trabalhador (QVT) enfermeiro, encontra-se prejudicada, entre outros fatores, devido à "ausência de perspectiva de ascensão na carreira"(18).

A última US resgatada nessa categoria é a Sobrecarga de Trabalho.

“... Em termos de Qualidade de gerenciamento é verificar se há uma cobrança muito grande, não é cobrança, mas é uma sobrecarga de atividades para as pessoas, para os profissionais para atender outros interesses... Avaliar qual a condição real do desenvolvimento das atividades em termos de sobrecarga..." [E4]

Felli e Tronchin ${ }^{(19)}$ consideram como um dos determinantes de um "perfil destrutivo" na QVT, a exposição dos trabalhadores de enfermagem às sobrecargas e subcargas Que geram processos de desgaste.

A outra categoria do estudo refere-se à Dimensão Profissional e agrega US, Que revelam como são percebidas, pelas colaboradoras, as vivências do trabalhador de enfermagem no seu cotidiano, aqui considerado "como uma atividade na Qual o trabalhador orientado por uma finalidade, transforma um determinado objeto de trabalho, em um produto final, utilizando meios e instrumentos, sob determinada organização, constituindo estes, em seus elementos"(20).

Sob essa ótica, o resgate de elementos constitutivos do processo de trabalho de enfermagem, por subsidiar e Qualificar as transformações das condições desse trabalho fornecem matéria prima para a construção de indicadores Que possibilitam a avaliação da Qualidade do gerenciamento do pessoal de enfermagem.

A US Absenteísmo integra a categoria Dimensão Profissional e é um tema Que vem sendo estudado pelas conseQüências negativas Que provoca no cotidiano do trabalho de enfermagem e aparece de forma acentuada nas falas das colaboradoras.

Os problemas vivenciados pelo pessoal de enfermagem no trabalho, somados aos pessoais, conduzem a uma sensação de impotência e insatisfação pessoal resultando no absenteísmo Que repercute, diretamente, na Qualidade da assistência prestada(21).

“... Eu acho importante que a gente até tem observado, mas não tem trabalhado na totalidade é o absenteísmo Que é, sem dúvida nenhuma, um outro indicador" (E5).

"Na minha visão precisa ser levado em consideração, para avaliar a Qualidade do gerenciamento de $\mathrm{RH}$ em enfermagem, o absenteísmo, ou seja, as ausências desses funcionários" (E8).

“... Isso também faz parte de um indicador a ser reconhecido: o índice de absenteísmo" (E9).

Outra US que emergiu dos discursos foi Rotatividade do Pessoal. Em relação aos fatores Que determinam este indicador encontramse os elementos como o salário, a motivação, o enfado na execução de tarefas e o reconhecimento profissional. As falas a seguir mostram alguns aspectos dessa situação:

“... Especificamente no gerenciamento de $\mathrm{RH}$ eu tenho a impressão Que se nós analisarmos a rotatividade de pessoal, por exemplo, é um indicador". (E3)

“Outro aspecto importante é a taxa de rotatividade..." (E5)

O Número de Horas de Treinamento aparece, nas falas das colaboradoras do estudo, como uma US da categoria Dimensão Profissional. Este achado, referenda dados encontrados em outras pesquisas que consideram o número de horas de treinamento/ funcionário/ano como um dos Indicadores consagrados para avaliar a Qualidade do gerenciamento de $\mathrm{RH}^{(9)}$.

Assim, E3 afirma:

"A capacitação e treinamento de pessoal poderia ou entraria como um indicador de $\mathrm{RH}$ ".

Entretanto, constata-se em algumas falas, Que as docentes consideram Que o treinamento do pessoal de enfermagem tem ocorrido de forma, predominantemente, focada no desenvolvimento de competências técnico-científicas e sugerem Que a capacitação se dê, também, no foco das competências sócio-educativas e éticopolíticas.

Os discursos, a seguir, explicitam esse contexto:

“... A educação, a formação dos $\mathrm{RH}$, como eles desenvolvem a prática... Acredito Que é uma Qualificação não só em relação aos procedimentos, mas uma Qualificação relacionada também às relações, como ele estabelece as relações tanto com o usuário Quanto com o grupo de trabalhadores de enfermagem".(E2)

“... A gente vê muito o treinamento sendo voltado para a parte técnica... A Questão da realização dos procedimentos... Eu acho muito importante, também, ver essa parte do aspecto relacional". (E4)

Compondo, também, a categoria Dimensão Profissional foi resgatada a US Satisfação no Trabalho. Martinez et al. ${ }^{(22)}$ em estudo realizado, consideram Que os elementos geradores da satisfação no trabalho estão relacionados ao próprio trabalho e ao seu conteúdo; às possibilidades de promoção; às condições ambientais do trabalho; ao relacionamento com os colegas e subordinados; às características da supervisão e do gerenciamento e às políticas e 
competências da organização.

Referenciando esta US, um aspecto Que chama a atenção na fala de E5 diz respeito à dificuldade em mensurar a satisfação do trabalhador como um indicador de Qualidade de gerenciamento.

"A gente tem um pouco mais desenvolvido para trabalhar com os usuários externos, com os usuários internos a gente tem pouca coisa para trabalhar nesse sentido, então eu acho Que é um indicador complexo de ser trabalhado, de medir satisfação (do trabalhador), mas é importante".(E5)

"Quando você está dando uma assistência qualificada, é mais um indicador de Qualidade de satisfação do trabalhador. Eu levo em consideração, assim, a satisfação ou insatisfação do trabalhador". (E )

A colaboradora E 10 correlaciona satisfação com QVT, onde o trabalho de enfermagem é determinado pelas contradições existentes entre os aspectos saudáveis Que o grupo desfruta e aspectos destrutivos de Que padece ${ }^{(19)}$.

"Quando estou falando de indicadores psicossociais entra a satisfação no trabalho, da família, dos clientes, da equipe multiprofissiona". (EI0)

Uma outra US considerada como integrante de um indicador de Qualidade de gerenciamento de RH são os Acidentes de Trabalho.

Silva ${ }^{(23)}$, em pesquisa realizada com trabalhadores de enfermagem, concluiu Que os ferimentos pérfuro-cortantes e as doenças ósteo-músculo-articulares aparecem como danos característicos desse grupo de trabalhadores.

“... Os tipos de indicadores que se poderia pensar: número de acidentes por grupos de trabalhadores; eu acho que diferenciando entre as categorias é um dado importante; não só o número de acidentes, mas, também, o número de problemas de saúde no trabalho". (E2)

Finalmente, a US Que compõe a Categoria Dimensão Profissional aparece, nas falas das colaboradoras, o Afastamento por Doenças.

$\mathrm{O}$ depoimento de E2 mostra a responsabilidade do gerenciamento Quando diz;

“... A gente sabe que a escassez de RH é muito grande e muito relacionada a problemas de saúde do trabalhador, Que acaba implicando, também, na Qualidade da assistência... Eu acho Que o absenteísmo por doença... Conseguir identificar que doenças, Quais as condições de trabalho Que poderiam estar minimizando os problemas de saúde do trabalhador".

Felli e Tronchin ${ }^{(19)}$ ratificam essa fala Quando considera Que "o entendimento dos problemas de saúde vivenciados pelos profissionais de enfermagem deve ser buscado na internalidade do processo de trabalho, o Que permite uma visão ampliada da realidade e a possibilidade de resolutividade dos agravos de saúde focada no coletivo dos trabalhadores".

\section{CONSIDERAÇÕES FINAIS}

A análise do material coletado junto às docentes que militam na área do ensino da Administração em Enfermagem permitiu o resgate de elementos significativos, com os Quais se procura "dar conta das principais variáveis Que orientam as decisões conceituais e metodológicas na construção dos processos de avaliação em saúde"(3).

Assim, a elaboração das Categorias Dimensão Institucional e Dimensão Profissional evidenciam os dois eixos ou pólos Que, dialeticamente, estão presentes na dinâmica do trabalho coletivo em saúde. As US albergadas nessas categorias resultam na produção de um conhecimento Que serve como fator orientador na construção de indicadores para a avaliação da Qualidade do gerenciamento de RH em enfermagem e em saúde Que deverão responder aos atributos de validade, sensibilidade, especificidade, simplicidade e objetividade $^{(5)}$.

Os depoimentos permitiram evidenciar indicadores, anteriormente, consagrados por sua utilização como o número de horas de treinamento/funcionário e investimento institucional/funcionário, como, também, propõem indicadores como absenteísmo e rotatividade. Embora estes dois indicadores já tenham sido investigados na sua dimensão Quantitativa, carecem de investigação na dimensão Qualitativa, uma vez Que as intervenções gerenciais devem considerar, para sua efetividade, o conhecimento das causas e dos motivos que levam o trabalhador ao absenteísmo e à rotatividade.

Outros significados atribuídos para a construção de indicadores dizem respeito à saúde do trabalhador e a QVT. A adoção do número de Afastamentos por Doença ou de Acidentes de Trabalho como prováveis indicadores é válida. Entretanto, esses dados podem estar comprometidos devido às falhas na notificação desses eventos.

A Remuneração AdeQuada e a Progressão na Carreira, também, são propostas resgatadas como possíveis indicadores de Qualidade no gerenciamento de RH. Sem dúvida, estas propostas explicitam a necessidade do profissional ser reconhecido como elemento de essencialidade no contexto organizacional.

Quanto à proposta do construto Satisfação no Trabalho como um indicador de Qualidade carece de estudos Que verticalizem e decodifieuem o real significado desse sentimento, segundo a vivência e percepção dos enfermeiros, para Que possa ser adotado de forma Quantifícável.

Os prováveis indicadores sugeridos, neste estudo, deverão ser aplicados e validados em diferentes realidades, para Que possam atender aos atributos específicos de um indicador de Qualidade.

\section{REFERÊNCIAS}

1. Donabedian A. The seven pillars of Quality. Arch Pathol Lab Med 1990; 14(11): 1115-8.
2. Gastal FL. Controle estatístico de processo: um modelo para a avaliação da Qualidade de serviços de internação psiQuiátrica 
[tese]. São Paulo (SP): Universidade Federal de São Paulo, Escola Paulista de Medicina; 2001.

3. Novaes HMD. Avaliação de programas, serviços e tecnologias em saúde. Rev Saúde Pública 2000; 34(5): 547-9.

4. Joint Commission. Characteristicas of clinical indicators. QRB Qual Rev Bull 1989; 15(1 1): 330-9.

5. Bittar OIN. Indicadores de Qualidade e Quantidade em saúde. Rev Adm Saúde 200 I; 3(12): 2 1-8.

6. Kluck M. Indicadores de Qualidade para assistência hospitalar. [citado em: 2 abr 2007]. Disponível em: http:// www.cih.com.br/indicadores.htm

7. Leitão RER, Kurcgant P. Qualidade na prática gerencial da Enfermagem. Niterói (RI): Intertexto; 2004.

8. Malik AM, Schiesari LMC. Qualidade na gestão local de serviços e ações de saúde. São Paulo (SP): Faculdade de Saúde Pública, Universidade de São Paulo; 1998.

9. Jericó MC, Castilho V. Análise de alguns indicadores relacionados aos recursos humanos de uma organização hospitalar. Nursing 2004; 74:23-7.

10. Programa de Qualidade Hospitalar (CQH). Manual de Indicadores de Qualidade de Enfermagem. São Paulo: APM; 2006.

11. Mendes-Gonçalves RB. Tecnologia e organização das práticas de saúde: características tecnológicas do processo de trabalho na rede estadual de centros de Saúde de São Paulo. São Paulo: Hucitec-Abrasco; 1994.

12. Ministério da Saúde (BR). Conselho Nacional de Saúde. Resolução n. 196, de 10 de outubro de 1996. Dispõe sobre diretrizes e normas regulamentadoras de pesquisas envolvendo seres humanos. Bioética 1996; 4(2 Supl): 15-25.

13. Bardin L. Análise de conteúdo. Lisboa: Edições 70; 1977.
14. Gaidzinski RR, Fugulin FMT, Castilho V. Dimensionamento de pessoal de enfermagem em instituições de saúde. In: Kurcgant P, coordenadora. Gerenciamento em enfermagem. São Paulo: Guanabara Koogan; 2005. p. 125-37.

15. Castilho V, Gonçalves VLM. Gerenciamento de recursos materiais. In: Kurcgant P, coordenadora. Gerenciamento em enfermagem. Rio de Janeiro: Guanabara Koogan; 2005. p. 157 70.

16. Kurcgant P. O poder nas relações multiprofissionais. In: Kalinowski CE, coordenadora. Programa de Atualização em Enfermagem Saúde. Porto Alegre: Artmed; 2007. p.9-21.

17. Robbins SP. Comportamento organizacional. $9^{\mathrm{a}}$ ed. São Paulo: Prentice Hall; 2002. p. 77-129.

18. Vieira DF. Qualidade de vida no trabalho dos enfermeiros em hospital de ensino [dissertação]. Porto Alegre (RS): Universidade Federal do Rio Grande do Sul, Faculdade de Ciências Econômicas; 1993.

19. Silva VEF, Kurcgant P, Queiroz VM. O desgaste do trabalhador de enfermagem: relação trabalho de enfermagem e saúde do trabalhador. Rev Bras Enferm 1998; 5 I (4): 603-I4.

20. Marx K. O capital: crítica da economia política. $3^{a}$ ed. São Paulo: Nova Cultural; 1988.

21. Faria AC, Barbosa BD, Domingos NAM. Absenteísmo por transtornos mentais na enfermagem no período de 1996 a 2004. Are Ciênc Saúde 2005; 12 (1):14-20.

22. Martinez MC, Paraguay AIBB, Latorre MRDO. Relação entre satisfação com aspectos psicossociais e saúde dos trabalhadores. Rev Saúde Pública 2004;38 (1):55-61.

23. Silva VEF. O desgaste do trabalhador de enfermagem: relação trabalho de enfermagem e saúde do trabalhador [tese]. São Paulo (SP): Escola de Enfermagem da USP, Universidade de São Paulo; 1996. 